\title{
Modelling consumer's intention to use IoT devices: role of technophilia
}

\author{
Nusrat Jahan', Md. Abu Hosen Shawon ${ }^{2}$, Farzana Sadia ${ }^{3}$, Dilara Khanom Nitu ${ }^{4}$, \\ Md. Enam Kobir Ribon ${ }^{5}$ Imran Mahmud ${ }^{6}$ \\ 1,3,4,5,6 Department of Software Engineering, Daffodil International University, Bangladesh \\ ${ }^{2,6}$ Department of Information Technology \& Management, Daffodil International University, Bangladesh \\ ${ }^{6}$ BRAC Business School, BRAC University, Bangladesh \\ ${ }^{1,3}$ School of Computer \& Communication Engineering, Universiti Malaysia Perlis (UniMAP)Title should
}

\begin{tabular}{|c|c|}
\hline Article Info & ABSTRACT \\
\hline Article history: & The present study has been conducted to examine whether skills and general \\
\hline Received Mar 26, 2021 & $\begin{array}{l}\text { technology-related value (GTV) required to operate the internet of things } \\
\text { (IoT). This study also investigates is there any effect of technophilia to adopt }\end{array}$ \\
\hline Revised May 19, 2021 & IoT. The research method we use in this quantitative study was the sample \\
\hline Accepted Jun 24, 2021 & $\begin{array}{l}\text { survey. For investigating results, } 352 \text { surveys were conducted where } 26 \\
\text { surveys were led through online and } 292 \text { surveys were distributed to different }\end{array}$ \\
\hline Keywords: & $\begin{array}{l}\text { age groups. The proposed model was examined using partial least square } \\
\text { structural equation model where the results revealed that IoT skills and }\end{array}$ \\
\hline $\begin{array}{l}\text { IoT } \\
\text { IoT adoption } \\
\text { IoT in Banoladesh }\end{array}$ & $\begin{array}{l}\text { General knowledge on technology directly contribute to technophilia which } \\
\text { covers behavioural, emotional, and cognitive aspects. That is if people have a } \\
\text { fascination for new technologies, then they are willing to use IoT. }\end{array}$ \\
\hline
\end{tabular}

This is an open access article under the $\underline{C C B Y-S A}$ license.

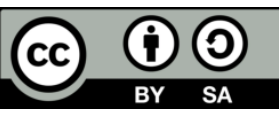

\section{Corresponding Author:}

Md. Abu Hosen Shawon

Department of Software Engineering

Daffodil International University, Bangladesh

Email: hosen35-1420@ diu.edu.bd

\section{INTRODUCTION}

IoT refers to the network of some objects which contain sensors, software to connect data with other devices over the internet [1]. By gathering and synchronising big data with the cloud system and processing them in intelligent devices internet of things (IoT) generates innovative values in the smart linked world. By using IoT solutions a number of devices connected people, networks, data. It is predicted that by 2030 there will be over 500 million products or devices available that are connected through internet [2]. Though IoT technologies and products are available, it is not widely accepted by end users. For this reason, it is necessary to find out which factor helps end users to use IoT device.

The principal purpose of the study is to scrutinize the aspects which are considered to influence the decisions of whether or not to take on IoT critically. It is conceivable to create a linked world with powerful new services and products by entangling radio frequency identification (RFID) i.e. biometric sensors and actuators which would gather, surveil and regulate data of the realtime world into the information technology framework. To be enabled to capture and connect with the realtime sensor data of the physical world 'smart' is coupled with the hardware, software and cloud detecting technologies which could similarly be used for advanced scrutiny and opting intelligent decisions [3]. IoT being interlinked with the group of connected smart devices could be addressed individually and communicated-with in realtime via standard IP centred 
communication protocols in terms of valid measurement for predicting user acceptance [4]. The technophilia which is considered as the autonomous determining factor of using a proposed new model amongst other potential determinants could be distinguished from the social standards and general discriminant technologyrelated values [5]. It is noteworthy that since the model could join up with the multi-tiers view of technology adoption, which also consists of single as well as organizational levels along with the national level view, it was termed as 'technophilia'. New perceptions might be invented through this model provided the user has the technological know-how, digital literacy, innovative mindsets, management, and adjustments in the technological context. The researchers [5] adduced that a general perspective on technology-related value (GTV) shares a common factor e.g. cognitive emotions towards the technology i.e. interest in, passion for technology, and level of information about. Nevertheless, these cognitive inclinations towards technology could strongly fluctuate depending on the device. They show that technophilia has a very important role to play in expanding the use of advance traveler information system (ATIS). They surveyed 1300 Austrian people to find out their attraction towards ICT through technophilia. Surprisingly GTV is not pertinent to the technology equally which are different. It is axiomatic that technology is the most significant factor in economic progress [6]. When information and communication technology (ICTs) is developed and becomes limitless in developed countries, it becomes very significant to the countries which are not that well-off as well due to the rapid spreading of the technology.

The researchers opined that cutting-edge technology could help to generate innovative services and devices depending upon the ever-changing demands of the current age consumers, for instance, augmented reality, 3D printers, and the device with an option to be worn [7]. Notwithstanding, modern age technologies like IoT has its convenience, it comes along with a threat to the security infrastructure [8]. Nevertheless, a distinctive line to be drawn between the technophilia- an interest and passion towards the latest ICT and GTV- mirroring worldwide beliefs in societal development. The critic [9] investigate for the acceptance of smart homes and explore some factors like risk, trust, awareness, and enjoyment that influence on the acceptance. They surveyed 258 people and showed that people's sentiment or objective to use smart homes. The term 'Smart Home' is used to describe a house, which interacts with a network that connects different devices and let themselves to be controlled, monitored, and accessed remotely. Smart devices are connected with the internet and Smartphone applications (remote) for the allowance to access. The current government of Bangladesh emphasises the development of the social and financial status of the country with the assistance of the state of art technology and progress onto the next level. Government establishes procurement plans based on ICT to work accordingly for the improvement of the country. Highlighting the plans of government, IoT and technophilia plays a significant role in the field of skill development, employment generation, Social equality, digital government, digital security and many others [10]. By the end of 2021, the Government aims to establish a Digital Bangladesh (Modern country). The company Data-Soft Launches its first IoT Lab in Bangladesh. The government also focuses on to increase the total number of internet users. The government also built a Hi-Tech Park and providing free IT courses for enthusiastic and technophile citizens of Bangladesh [11].

In the research article authors use expanded technology acceptance model (TAM) that goes into the importance of IoT (internet of things) [12]-[14] skills for the adoption of IoT technology. They also produced some requirements for increasing IoT adoption internet skills like Mobile, information navigation, social and skills. Yildirim and Ali-Eldin [15] they propose conceptual model which define some factors that influence users to use wearable IoT devices at workplace. The authors proposed a new refuge to IoT-based [16] smart home service acceptance using value-based adoption model (VAM) [17], [18] and technology acceptance model (TAM) [19]. In this exploration paper critics portray that acknowledgement of IoT is as yet restricted to a couple of application areas and a few examinations show that seek after the acknowledgement of IoT from numerous hypothesis viewpoints, in particular, the theory of reasoned action (TRA), the theory of planned behavior (TPB) [20] and TAM. In this exploration paper critics [21] investigate the meticulousness of the TAM [22] utilizing members in an educational setting and the spread to which unusual factors impacts on the model (TAM). Furthermore, it investigates the capacity of innovation for changing educating and learning. He shows that tutors don't utilize innovation viably as the utilization of PCs in the study halls stays specific and insignificant. The author [23] broaden the essential TAM model by examining the effect of factors trust, perceived conduct control and abstract standard on worker's demeanour and social expectation towards embracing IoT in retail situations. The primary reason for the paper is to recognize factors critical to the acknowledgement and utilization of IoT by retail representatives and to suggest the board methodologies for powerful IoT incorporation in the retail stores. Author measure their view of IoT as far as handiness, Ease of Use, trust, views towards IoT reception, saw conduct control, emotional standard and social goal. By using this survey models'experts perceived that constitution and protection of the appropriate framework for the residents to use IoT based home services are indispensable for the business. Technophobia (dismissal of innovation) and technophilia (appreciation for innovation) [24] are the two limits of the connection between innovation and the individual, however especially, among innovation and society. The critic [25] proposed another model 
(technophilia) for innovation acknowledgement and perceive the reception procedure itself as a key factor for efficacious deep-rooted utilization of running innovation, for example, salary level, abilities, formal instruction, or hands-on preparing and it's (technophilia) notice to ICT including IS, cell phones, advanced diversion and Internet sites. Also, it's appeared to be good as the model might be further intricate to different sorts of innovation. The author [24] has also portrayed about Modern advances face of the mental debate since, current innovations produce in a similar measurement, solace and catastrophes. He similarly said that at the psychodynamic level, this inner conflict is communicated by fascination in innovation and dismissal of innovation. The critic [24] proposed an IoT adaption model that work of three innovation factors dependent on innovation adaption model (TAM) that focus to create and test an integrative model of variables deciding customers' adaption of IoT innovation and it's have been given wide consideration and had the huge number of adaptions in numerous fields. The study is led to the individuals who intend to approach this perplexing discipline and contribute towards its progressions. IoT adoption mostly depends on the intention to use (IU) and technophilia. IU depends on perceived risks, trust, awareness, and IoT Skills [25]. Technophilia depends on social standard towards ICT and GTV value. This study endeavours to discover the elements that influence technophilia and the factors which are reliant on IoT adoption in Bangladesh. Furthermore, a new model for technology adoption would be presented. Calculation of the elements that influence the acceptance of IoT would be emphasized on through limited research. Therefore, the first question of the research (RQ) would be:

RQ 1. Do IoT skill and general technology-related value moderate the relationship between technophilia and IoT adoption behaviour. Secondly, this study investigates whether or not there is any impact of technophilia on IoT adoption i.e. technophilia's influence on intention to use IoT is measured. RQ 2. Is technophilia a driver for IoT adoption of the users?

The introduction section defines the term technophilia, IoT, smart home. It also helps to find out why IoT is important in daily life and which factor influence IoT adoption. The research model and hypothesis part describe model with the hypothesis whereas research method part describe questionnaire design. Result and discussion part describes measurement model and structural model and discussion of those model is given in discussion section.

\section{RESEARCH MODEL AND HYPOTHESIS}

An integrated research model is anticipated here to examine the factors for adopting IoT. This research model covers two things one is, GTV and IoT contribute to technophilia whereas technophilia depends on three factors named techno-E, techno-B, and techno-C [5]. The subsequent Figure 1 provides a portrait of the proposed research model.

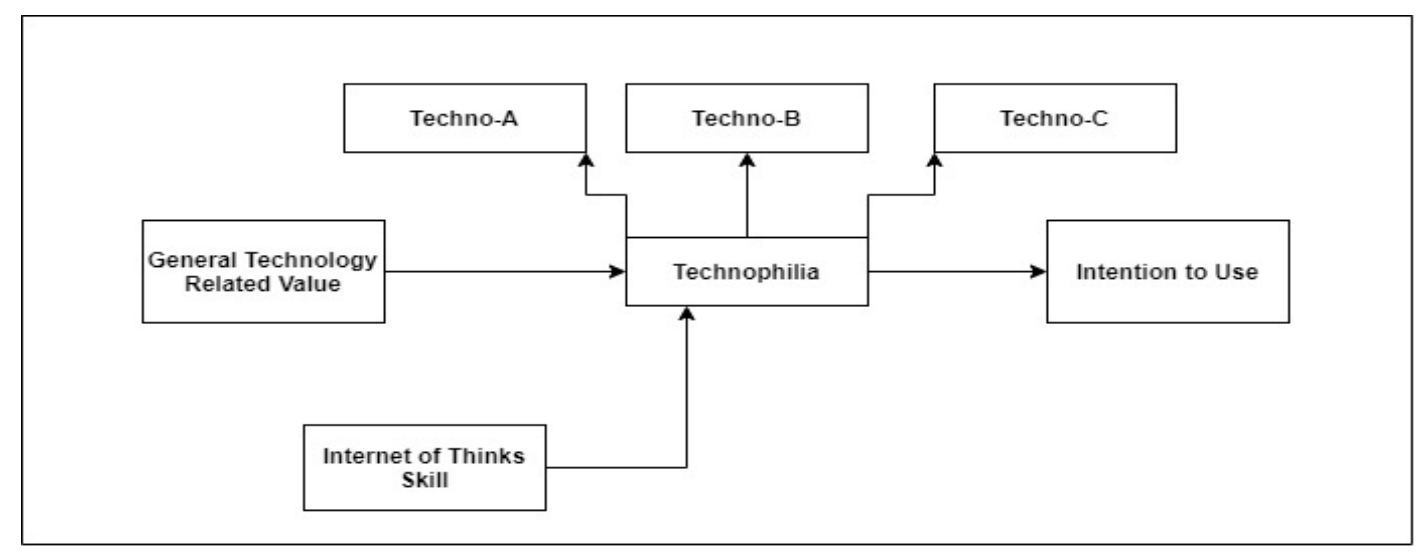

Figure 1. Proposed model

The proposed research model has been summed up dependent on the theories. In this model, technophilia is subject to GTV and IoT which implies that the absence of comprehension is along these lines reflected in challenges in thinking in regards to gadgets' cooperation and their belongings, which, thus, lead to inadequate details and error. Coming up short on the abilities to accurately decipher, examine, and convey information could bring about clients gathering superfluous information, overlooking to apply the information, or making an erroneous inference. 
- H1. General Technology related value has a positive impact on technophilia.

- H2. IoT Skills has a positive impact on technophilia.

- An expectation to utilize IoT gadgets subject to technophilia which envelops three attitudinal aspects i.e., behavioural, emotional, and cognitive components. Psychology and passion bring excitement and create enthusiasm for innovation.

- H3. technophilia (behavioural, emotional, cognitive) has positive impact on IU.

\section{RESEARCH METHOD}

\subsection{Study design, participants and demographics}

The participants of this research were the individual consumers who visited electronic stores to purchase any electronic items. The minimum sample size with a predictive power of 0.95 was arrived at by following the research of [26], [27]. Calculations suggested that with a maximum of two predictors ((GTV and IOTS), the required sample size was 129 . Output was estimated minimum sample size required was 117 , with actual power of $95 \%$. Still, distributed questionnaires are 352 where 318 are respondents completed the form completely. The respondents' age in between (20-29, 30-39, 40-49, 50 and above). Received response rate $90.34 \%$. Respondents square measure typically university undergrad and master level students, job holder and academics. Out of 318 responding individuals, almost $210(66.0 \%)$ were 20-29 years old, (18.6\%) were 30-39 years old, $34(10.7 \%)$ were $40-49$ years old while the remaining $15(4.7 \%)$ were above the age of 49 . In regard to gender, $201(63.2 \%)$ were male and 117 (36.8\%) were female. See Table 1.

Table 1. demographic information of survey respondents

\begin{tabular}{ccc}
\hline Age & Frequency & Percentage (\%) \\
\hline $20-29$ & 210 & 66.0 \\
$30-39$ & 59 & 18.6 \\
$40-49$ & 34 & 10.7 \\
$50-59$ & 15 & 4.7 \\
& & \\
Gender & & 63.2 \\
Male & 201 & 36.8 \\
Female & 117 & \\
\hline
\end{tabular}

\subsection{Questionniare design}

Data was collected using a structured questionnaire. The questionnaire consisted of two parts: The first part focused on demographic questions like age, gender, level of education, and experience of basic IoT related devices. The second part focused on measurement items for the dimensions of IoT skill related questionnaire were adopted from the research of [12]. Technoplilia, General technology related value, and intention to use (IU) were adopted from the research of [5]. All statements were measured through the likrt seven-point scale (1-strongly disagree; 7-strongly agree). See Table 2 for details questionnaire and source

Table 2. Measurement items

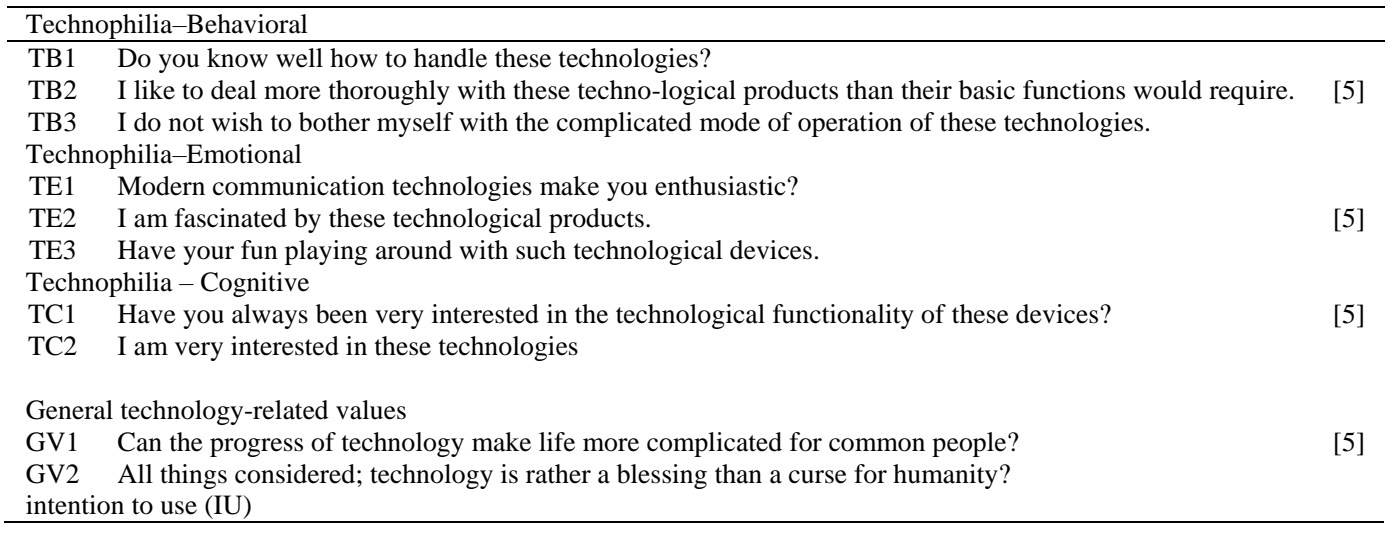


Table 2. Measurement items

\begin{tabular}{ll}
\hline \multicolumn{2}{c}{ Technophilia - Behavioral } \\
\hline IU1 & By offering, I intend to use Smart Homes. \\
IU2 & I am willing to use Smart Homes in the near future. \\
IU3 & I would recommend Smart Homes to others. \\
IU4 & If I have smart home objects, I would subscribe in Smart Homes. \\
IOT Skills \\
Q1 & Do you know how to connect smart device to the Internet? \\
Q2 & Do you know how to share information from smart devices on the Internet? \\
Q3 & Do you know how to operate smart devices by using applications? \\
Q4 & Do you know how to interpret data from smart-devices? \\
Q5 & Do you know how to connect smart devices to my Wi-Fi network? \\
Q6 & Can you find it hard to decide on the best settings for smart devices@? \\
Q7 & Can you feel confident operating smart devices? \\
Q8 & Can you find the way smart devices operate unclear? \\
Q9 & Do you know how to change with whom I share data on a smart device? \\
Q10 & Do you know how to read data from smart devices? \\
Q11 & Do you know how to change how often data are gathered by smart devices? \\
\hline
\end{tabular}

\subsection{Data analysis strategy}

Based on the study by [26], PLS-SEM able to overcome the first-generation method which able to extend the evaluation data quality through the measurement model. In this paper, structural equation modelling (SEM) is utilized to quantify the relationship among the factors of our projected model. SEM permits the analyst to extensively and concurrently investigate a perplexing model with various autonomous and nonautonomous factors [26]-[30]. Therefore, information system (IS), business management, and social science researchers utilise this strategy [33] extensively [34], portrayed that: from 1998 to 2007, 33.3\% of journals in the ISR, $34.5 \%$ in the JMIS, and 32.2\% papers used SEM methods. McDonald and Ho stated that the partial least squares (PLS) approach is viewed as the most exhaustive and an expansive strategy. PLS is portrayed as a 'Silver bullet' by Joe. F, Hair Jr, Marko Sarstedt, Lucas Hopkins, Volker G. Kuppelwieser. as PLS can deal with non-nominal data. With an intention to test the proposed speculations, SEM is utilized to evaluate an exploration model and empower to execute different complex measurable examinations rapidly. It is a regression-based methodology that characterizes the relationship among the observed factors [33] and targets to limit the remaining variances of endogenous factors [34]. For estimating our model here SEM with the PLS procedure [35] and SmartPLS3 software is utilized to compute the data.

\section{RESULT AND DISCUSSIONS}

\subsection{Measurement model}

The researcher [35] recommend that after the examination model is shaped, researchers must test the outer model. Measurement model gives two sorts of analysis (Reliability and Validity). Reliability investigation gives yield about Composite Reliability and validity analysis provide the outcome to average variance extracted (AVE) [35]. For assessment of the outer model, the average variance expected (AVE), composite reliability (CR), and discriminant validity is estimated that has appeared in Tables 3 and 4.

Table 3 shows that the square root of AVE is more prominent than the corresponding construct correlation, which demonstrates that our construct is particular from different develops [36]. The correlation values should be greater than among other latent variables [37]. Table 4 shows these values.

Table 3. Construct reliability and validity table

\begin{tabular}{ccc}
\hline Variables & Composite Reliability & Average Variance Extracted (AVE) \\
\hline GTV & 1.000 & 1.000 \\
IOTS & 0.913 & 0.570 \\
IU & 0.911 & 0.720 \\
TF & 0.876 & 0.704 \\
\hline
\end{tabular}

Table 4. Discriminant validity (fornell-larcker criterion) table

\begin{tabular}{ccccccc}
\hline Variables & GTV & IOTS & IU & TBQ & TCQ & TEQ \\
\hline GTV & 1.000 & & & & & \\
IOTS & 0.086 & 0.755 & & & & \\
IU & 0.201 & 0.174 & 0.849 & & & \\
TBQ & 0.163 & 0.391 & 0.266 & 0.824 & & \\
TCQ & 0.160 & 0.141 & 0.427 & 0.424 & 0.900 & \\
TEQ & 0.223 & 0.171 & 0.450 & 0.566 & 0.700 & 0.831 \\
\hline
\end{tabular}




\subsection{Structural model}

After analysing the AVE along with the reliability and legitimacy of data, structural model is used by utilizing the assessment coefficient of determination and the significance level of each path coefficient. Here, pvalue is additionally inspected to decide the implication of the level. P-value is acknowledged whether it tends to be smaller than 0.5 or bigger than 0.95 [38]. Support of speculation is dictated by the significance level of each path coefficient. This implies, concerning our model (see Table 4), the connection between GTV and IoT on TF, TF on IU to Use. GTV $(=0.196, p \leq 0.01)$ and IoT $(=0.226, p \leq 0.01)$ has huge impact on TF. Subsequently, H1 and $\mathrm{H} 2$ are bolstered. Support of hypothesis is determined by the significance level of each path coefficient. This means, as to our model, the relationship between TF on IU is TF $(=0.462, p \leq 0.01)$. This also demonstrates our hypothesis $\mathrm{H} 3$ is significant. Table 5 shows the significance of each path in the investigation.

Table 5. Results of hypothesis testing

\begin{tabular}{cccc}
\hline Hypothesis & Relationships & Path coefficient & Result \\
\hline H1 & GTV $->$ TF & 0.196 & Supported \\
H2 & IOTS $>$ TF & 0.226 & Supported \\
H3 & TF $->$ IU & 0.462 & Supported \\
\hline
\end{tabular}

\section{DISCUSSION}

This research contributes to the structure of work consecrated to serving researchers better understand IoT adoption. It expressed the primarily micro-level investigation of IoT adoption through the lens of technophilia by building on the understanding of the phenomenon at the consumer level. In case of influence of GTV on IF, the hypothesis is supported. It is obvious that if higher level of generic technology view will lead higher level of technophilia. People concerned with technology will be excited to use more internet-based technology. From the second hypothesis, we can conclude that IoT skills contribute to the use of the IoT. IoT skills contribute both directly and indirectly, indicating that people's assessments of their own capabilities in using the IoT are important for actually starting to use the IoT. This result is aligned with the research of [12].

\section{CONCLUSION}

This exploration study proposed a coordinated model that uncovers the elements of receiving or discovering goal to utilize IoT innovation in Bangladesh. Most of the hypothesis has been supported by the data that concludes that people's IoT skills play an important factor for technophilia. Technophilia is used for better understanding of new technology. In future we will analyze large amount of data and variables like technostress, product innovation and consumer motives on IoT device adoption. We will also make a model including variables like: trust, risk, awareness. This research will help with manufacturers to understand their view of IoT design, develop compelling advertisement of technophile adopters and improve client section. IoT structure should indicate requirements of technophile users. It can also assist the IoT manufacturing organizations to understand consumers' response to new technologies like IoT devices.

\section{REFERENCES}

[1] M. C. Türkeș, S. Căpuşneanu, D. I. Topor, A. I. Staraș, M. Ș. Hint, and L. F. Stoenica, "Motivations for the Use of IoT Solutions by Company Managers in the Digital Age: A Romanian Case," Applied Sciences, vol. 10, no. 19, pp. 6905, 2020, doi: 10.3390/app10196905.

[2] CISCO, "Internet of Things: At-a-Glance," CISCO: San Jose, CA, USA, 2016.

[3] T. Nam and T. A. Pardo, "Conceptualizing smart city with dimensions of technology, people, and institutions," Proceedings of the 12th annual international digital government research conference: digital government innovation in challenging times, 2011, pp. 282-291, doi: 10.1145/2037556.2037602.

[4] F. D. Davis, "Perceived usefulness, perceived ease of use, and user acceptance of information technology," MIS quarterly, pp. 319-340, 1989, doi: 10.2307/249008.

[5] S. Seebauer, S. Reginaand, and B. Martin, "Technophilia as a driver for using advanced traveler information systems," Transportation Research Part C: Emerging Technologies, vol. 60, pp. 498-510, 2015, doi: 10.1016/j.trc.2015.10.009.

[6] H. Farooq, H. U. R. Rehman, A. Javed, M. Shoukat, and S. Dudely, “A Review on Smart IoT Based Farming," Annals of Emerging Technologies in Computing (AETiC), vol. 4, no. 3, pp. 17-28, 2020, doi: 10.33166/aetic.2020.03.003.

[7] M. M. Zwick, O. Renn, M. Heinßen, A. Sautter, and E. Höhle, Perception and evaluation of risks: findings of the "Baden-Württemberg risk survey 2001, 2002, doi: 10.18419/opus-8684.

[8] V. Venkatesh, G. Michael, G. B. Morris, and F. D. Davis, "User Acceptance of Information Technology: Toward a Unified View," Management Information Systems Research Center, vol. 27, no. 3, pp. 425-478, 2003, doi: $10.2307 / 30036540$ 
[9] A. Shuhaibera and I. Mashal, "Understanding users' acceptance of smart homes," Technology in Society, vol. 58, p.101110, 2019, doi.org/10.1016/j.techsoc.2019.01.003.

[10] About Social equality, digital government, digital security, [Online]. Available: https:/ictd.portal.gov.bd/sites/default/files/files/ictd.portal.gov.bd/policies/0b508068.pdf. Accessed Sept. 15, 2019.

[11] About Hi-Tech Park, IT related free courses. [Online]. Available: https://www.slideshare.net/ApurboDatta1/internetof-thinngsbangladesh?qid=72f9dcd0-97e4-40bf-bd5a96c590000b6bv=b=fromsearch=2. Accessed Sept. 13, 2019.

[12] P. S. Boer, A. J. A. Deursen, and T. J. L. Rompay, “Accepting the Internet-ofThings in our homes: The role of user skills, Telematics and Informatics," Echnology in Society, vol. 58, pp. 147-156, 101110, 2019, doi: $10.1016 /$ j.tele.2018.12.004.

[13] L. Atzori, A. Lera, and G. Morabito, "The Internet of Things: A survey," Computer networks, vol. 54, no. 15, pp. 2787-2805, 2010, doi: 10.1016/j.comnet.2010.05.010.

[14] J. Gubbi, R. Buyya, S. Marusic, and M. Palaniswami, "Internet of Things (IoT): A Vision, Architectural Elements, and Future Directions. Computer Networks," Future generation computer systems, vol. 29, no. 7, pp. 1645-1660, 2013, doi.org/10.1016/j.future.2013.01.010,

[15] H. Yildirim and A. M. Ali-Eldin, "A model for predicting user intention to use wearable IoT devices at the workplace," Journal of King Saud University-Computer and Information Sciences, vol. 31, no. 4, pp. 497-505, 2019, doi: 10.1016/j.jksuci.2018.03.001.

[16] M. Mital, P. Choudhary, V. Chang, A. Papa, and K. Pani, "Adoption of Internet of Things in India: A test of competing models using a structured equation modeling approach, echnological Forecasting and Social Change," Technological Forecasting and Social Change, vol. 136, pp. 339-346, 2018, doi: 10.1016/j.techfore.2017.03.001.

[17] Y. Kim, Y. Park, and J. Choi, "A study on the adoption of IoT smart home service: using Value-based Adoption Model," Total Quality Management \& Business Excellence, vol. 28, no. 9-10, pp. 1149-1165, 2017, doi.org/10.1080/14783363.2017.1310708.

[18] H. W. Kim, H. C. Chan, and S. Gupta, "Value-based adoption of mobile internet: An empirical investigation," Decision Support Systems, vol. 43, no. 1, pp. 111-126, 2007, doi: 10.1016/j.dss.2005.05.009.

[19] K. Patil, "Retail adoption of Internet of Things: Applying TAM model," 2016 International Conference on Computing, Analytics and Security Trends (CAST), 2016, pp. 404-409, doi: 10.1109/CAST.2016.7915003.

[20] A. S. Ferdous, "Applying the theory of planned behavior to explain marketing managers' perspectives on sustainable marketing”, J. Int. Consum. Mark, vol. 22, no. 4, pp. 313-325, 2010, doi: 10.1080/08961530.2010.505883.

[21] M. Osiceanua, "Psychological implications of modern technologies: "technofobia" versus "technophilia"," ProcediaSocial and Behavioral Sciences, vol. 180, pp. 1137-1144, 2015, doi: 10.1016/j.sbspro.2015.02.229.

[22] P. Ronit, "Technophilia: A New Model for Technology Adoption," UK Academy for Information Systems Conference Proceedings, 2011.

[23] C. P. Lim and M. Khine, "Managing Teachers' Barriers to ICT Integration in Singapore Schools," Journal of technology and Teacher Education, vol. 14, no. 1, pp. 97-125, 2006.

[24] L. Gao, "A unified perspective on the factors influencing consumer acceptance of internet of things technology," Asia Pacific Journal of Marketing and Logistics, vol. 26, no. 2, 2014, doi: 10.1108/APJML-06-20130061.

[25] T. Prayoga and J. Abraham, "Behavioral intention to use IoT health device: The role of perceived usefulness, facilitated appropriation, big five personality traits, and cultural value orientations," International Journal of Electrical and Computer Engineering, vol. 6, no. 4, pp. 1751-1765, 2016, doi: 10.11591/ijece.v6i4.pp1751-1765.

[26] J. F. Hair, et al., "Executing and interpreting applications of PLS-SEM: Updates for family business researchers," Journal of Family Business Strategy, 2020, doi: 10.1016/j.jfbs.2020.100392.

[27] A. Alzahrani, I. Mahmud, R. Thurasamy, O. Alfarraj, and A. Alwadain, "End users' resistance behaviour paradigm in pre-deployment stage of ERP systems: evidence from Bangladeshi manufacturing industry," Business Process Management Journal, 2021, doi: 10.1108/BPMJ-08-2019-0350

[28] G. Singh, L. Gaur, and R. Ramakrishnan, "Internet of Things - Technology adoption model in India," Pertanika Journal of Science \& Technology, vol. 25, no. 3, pp. 835-846, 2017.

[29] F. Faul, E. Erdfelder, A. Lang, and A. Buchner, "G*Power 3: A flexible statistical power analysis program for the social, behavioral, and biomedical sciences," Behavior research methods, vol. 39, no. 2, pp. 175-191, 2007, doi: 10.3758/BF03193146.

[30] M. Consortium, "The MicroArray Quality Control (MAQC) project shows inter-and intraplatform reproducibility of gene expression measurements," Nature biotechnology, vol. 24, no. 9, p. 1151, 2006, doi: 10.1038/nbt1239.

[31] Kline, J, McGehee, M. D., Kadnikova, K. N, Liu, J, Fr'echet, and J. Toney, M, "Dependence of Regioregular Poly (3-hexylthiophene) Film Morphology and Field-Effect Mobility on Molecular Weight," Macromolecules, vol. 38, no. 8, pp. 3312-3319, 2005, doi.org/10.1021/ma047415f.

[32] G. Armstrong, "New Workforce, Practice, and Payment Reforms Essential for Improving Access to Pediatric Subspecialty Care Within the Medical Home," Arch Pediatr Adolesc Med., vol. 163, no. 3, pp. 200-202, 2009, doi: 10.1001/archpediatrics.2009.8.

[33] I. Mahmud, T. Ramayah, and S. Kurnia, "To use or not to use: Modelling end user grumbling as user resistance in pre-implementation stage of enterprise resource planning system," Information Systems, vol. 69, pp. 164-179, 2017, doi: 10.1016/j.is.2017.05.005.

[34] A. O'Gorman and R. Savithiri, "Hair tourniquet management," Pediatric emergency care, vol. 27, no. 3, pp. 203-204, 2011, doi: 10.1097/PEC.0b013e31820d65b7. 
[35] J. F. Hair Jr, M. Sarstedt, L. Hopkins, and V. G. Kuppelwieser, "Partial least squares structural equation modeling (PLS-SEM): An emerging tool in business research," European business review, vol. 26, no. 2, pp. 106-121, 2014, doi: 10.1108/EBR-10-2013-0128.

[36] A. Vafaei-Zadeha, T. Ramayah, H. Hanifaha, S. Kurniag, and I. Mahmud, "Supply chain information integration and its impact on the operational performance of manufacturing firms in Malaysia," Information \& Management, vol. 57, no. 8, 2020, doi: 10.1016/j.im.2020.103386.

[37] I. Mahmud, S. R. Das, S. Ahmed, S. C. J-Ho, and T. W. Andalib, "Fun or Frustration: Modelling Discontinuance Intention of Social Media Users," International Journal of Electronic Commerce Studies, vol. 11, no. 2, pp. 107-118, 2020, doi:10.7903/ijecs.1823.

[38] A. K. M. Z. Satter, A. Mahmud, A. Rahman, I. Mahmud, and R. Akter, "Civic engagement through restaurant review page in Facebook: a structural equation modelling approach," International Journal of Ethics and Systems, vol. 37, no. 2, 2021, doi: 10.1108/IJOES-06-2020-0078.

\section{BIOGRAPHIES OF AUTHORS}

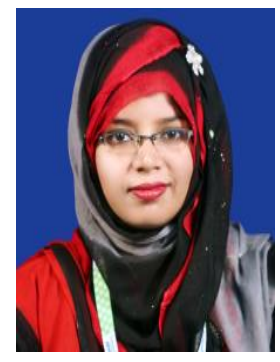

Nusrat Jahan is working as a Assistant Professor at department of Software Engineering in Daffodil International University in Bangladesh. She is currently pursuing her PhD from School of Computer \& Communication Engineering, Universiti Malaysia Perlis (UniMAP). She completed her M.Sc. and B. Sc. in IT from Institute of Information Technology, Jahangirnagar University and B.Sc. in Software Engineering from Daffodil International University. She is interested in technology management, computer networks, machine learning and artificial intelligence.

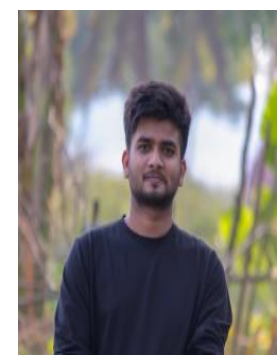

Abu Hossen Shawon is working as a student at department of Software Engineering in Daffodil International University in Bangladesh. He completed his B.Sc. in Software Engineering from Daffodil International University. He is interested in technology management.

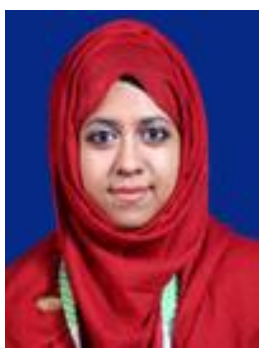

Farzana Sadia is is working as a Assistant Professor at department of Software Engineering in Daffodil International University in Bangladesh. She is currently pursuing her PhD from School of Computer \& Communication Engineering, Universiti Malaysia Perlis (UniMAP). She completed her M. Sc in Software Engineering from Independent University, Bangladesh. and B. Sc in Computer Science and Engineering, Ahsanullah University of Science and Technology. She is interested in technology management, computer networks, machine learning and artificial intelligence.

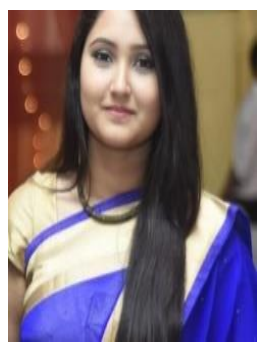

Dilara Khanom Nitu is working as a student at department of Software Engineering in Daffodil International University in Bangladesh. She is a current student of B.Sc. in Software Engineering from Daffodil International University. She is interested in technology management. 

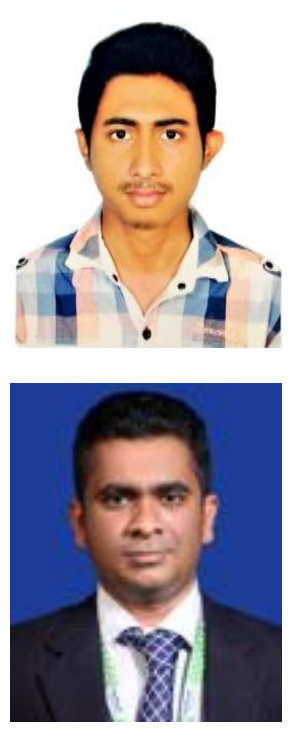

Md. Enam Kobir Ribon is working as a student at department of Software Engineering in Daffodil International University in Bangladesh. He is a current student of B.Sc. in Software Engineering from Daffodil International University. He is interested in technology management.

Dr. Imran Mahmud is an associate professor and head at Department of Software Engineering at Daffodil International University. He is also an associate director of research. Dr. Imran completed his $\mathrm{PhD}$ in technology management from Universiti Sains Malaysia. His research interests are human computer interaction, usability testing, software engineering measurement/models and management information systems. Dr. Imran has several research papers on Enterprise Resource Planning and information system published in Sage and IEEE. 